\title{
Survey of self-assessed preparedness for clinical practice in one Croatian medical school
}

\author{
Katarina Bojanic $^{\dagger 1}$, Gregory J Schears ${ }^{\dagger 2}$, Darrell R Schroeder ${ }^{\dagger 3}$, \\ Sarah M Jenkins ${ }^{\dagger 3}$, David O Warner ${ }^{\dagger 3}$ and Juraj Sprung* ${ }^{* \dagger 3}$
}

Address: ${ }^{1}$ Department of Obstetrics, Section of Neonatology, Merkur Clinical Hospital, Zagreb, Croatia, ${ }^{2}$ Department of Anesthesiology, Mayo Medical School, College of Medicine, Mayo Clinic, Rochester, MN, USA and ${ }^{3}$ Department of Health Sciences (Statistics), Mayo Clinic, Rochester, MN, USA

Email: Katarina Bojanić - sprungkatarina@hotmail.com; Gregory J Schears - schears.gregory@mayo.edu;

Darrell R Schroeder - schroeder.darrell@mayo.edu; Sarah M Jenkins - jenkins.sarah@mayo.edu; David O Warner - warner.david@mayo.edu; Juraj Sprung* - sprung.juraj@mayo.edu

* Corresponding author †Equal contributors

Published: 27 July 2009

BMC Research Notes 2009, 2:152 doi:10.1186/1756-0500-2-152
Received: 2 June 2009

Accepted: 27 July 2009

This article is available from: http://www.biomedcentral.com/l756-0500/2//52

(C) 2009 Sprung et al; licensee BioMed Central Ltd.

This is an Open Access article distributed under the terms of the Creative Commons Attribution License (http://creativecommons.org/licenses/by/2.0), which permits unrestricted use, distribution, and reproduction in any medium, provided the original work is properly cited.

\begin{abstract}
Background: The Croatian higher education system is in the process of reforming its medical curricula to comply with European Union standards. We conducted a survey of students enrolled at the University of Zagreb (Croatia) asking them to rate their perception of preparedness for clinical practice prior to initiation of the reform process. The purpose of the survey was to identify self-perceived deficiencies in education and to establish a reference point for the later assessment of ongoing educational reform.
\end{abstract}

Findings: One-hundred and forty seven $(N=147)$ graduates reported the levels of perceived preparedness on 30 items grouped into 8 educational domains. Main domains were: understanding science, practical skills/patient management, holistic care, prevention, interpersonal skills, confidence/coping skills, collaboration, and self-directed learning. For each item, graduates self assessed their preparedness on a scale ranging from I to 4, with I = "Very inadequate", 2 = "Somewhat inadequate", 3 = "Somewhat adequate", and 4 = "Very adequate". In 7 out of 8 domains the achieved median score was $\geq 3$. Students expressed low confidence (defined when $\geq 25 \%$ of respondents supplied a rating for the survey question as: "very inadequate" or "somewhat inadequate") with interpersonal skills (discussing terminal disease, counseling distraught patients, balancing professional and personal life), and in performing certain basic semi-invasive or invasive procedures.

Conclusion: Zagreb medical graduates identified several deficiencies within educational domains required for standard clinical practice. Ongoing educational efforts need to be directed towards the correction of these deficiencies in order to achieve standards required by the European Union.

\section{Introduction}

The main role of medical schools is to prepare students to function as competent physicians. Preparedness for practice is typically assessed and licensed via medical board (licensing) examinations. While these instruments aim to evaluate mastery of requisite medical knowledge, they are less able to assess other competencies important to practice such as communication, proficiency in physical exam- 
ination, ability to provide holistic care, and appropriate technical skills. These competencies are more difficult to measure, and the extent to which medical schools provide these skills to their graduates has seldom been studied[1]. In an effort to improve medical education and assessment of these skills, Objective Structured Clinical Examinations (OSCEs) have been introduced in both the United States and Canada which evaluate medical knowledge, clinical and communication skills at both graduate and postgraduate levels[2].

Self-evaluation, a form of assessment which tests an individual's subjective feelings regarding preparedness for tasks, has been used for formative assessment [3-5]. Some authors $[5,6]$ reported a reasonable agreement between trainees' estimates of their own abilities and their actual performance, while others did not [7-12]. While self-perceived assessment of competence may not always correlate with performance, particularly in those who perform poorly,[13] one recognized educational goal is improving students' belief that he or she is capable of attaining a certain goal ("self-efficacy")[14]. Therefore, it is important that medical educators identify areas of educational concern and then use this information to improve students' confidence[15]. The assessment of self-efficacy for clinical skills is increasingly relied upon by the curricular managers, alongside the measurement of observed competence to evaluate curricular success and guide teaching activities[16,17].

The Croatian system of medical education is presently undergoing major restructuring to harmonize students' performance with that in European Union.[18] The final document outlining these changes, denoted the Bologna Process Principles, $[19,20]$ was signed by Croatia in 2005. The fundamental purpose of Bologna reform is to place the student at the center of the learning process and improve the quality of academic programs. The primary aim of this initiative in the area of medical education is to improve curricular content and to increase direct student participation in patient care. In Croatia, this initiative substantially changed the method by which education is delivered. For example, preclinical education (first three years) has been changed from longitudinal (spread out form) to block/modular form. During subsequent clinical years (last 3 years of medical school), students receive lectures in block/modular form and receive clinical training in clinical skill labs and on patient wards. An emphasis is placed on small size teaching groups which increases interaction with teachers.

Croatian medical schools provided traditional teaching until 2006; after that time Bologna educational reform was initiated. Presently, we have no information whether Croatian graduates feel ready to work as junior doctors.
Availability of this information could help in designing new educational curricula. The purpose of this study was to assess the perception of the graduates of medical school in Zagreb, Croatia, regarding their readiness for clinical practice, and to establish a baseline for comparison once full implementation of Bologna education initiative is accomplished in the year 2012.

\section{Methods \\ Setting and Study Design}

In Croatia, the average age of the first year medical student is 18 years, and the education lasts 6 years. During the first 3 years, students take preclinical courses, which are structured longitudinally with a final exam after completion of the course. During the last 3 years, students are involved with clinical rotations. In the third year of medical school, students became gradually involved with patient care. Clinical rotations combine lecture-based education followed by short sessions (1-2 hours) on wards where they acquire practical skills working with patients. Therefore, Zagreb students lack longer patient contact that include follow-up from admission to discharge. During the ward sessions, students practice taking a medical history, performing a clinical exam, and at the end of the session the findings are discussed with their assigned physician/professor. Rarely do they perform simple surgical procedures, venipuncture, placement of urinary catheters, etc., and these interventions are mostly observed while performed by either a physician or ancillary staff.

To examine how Zagreb medical school graduating students perceive their preparedness to work as young doctors, we administered an anonymous paper survey entitled "Preparedness for Hospital Practice" [21] within a month before graduation in September 2006. Approval for administration of this survey was obtained from the Ethic Committee (Medical School Zagreb, Croatia).

\section{Survey Instrument "Preparedness for Hospital Practice"}

The survey assesses the subjective feelings of the graduates regarding their medical school educational achievements. This survey was originally designed and validated by Hill et al.[21] Questions are arranged in 8 domains of educational goals that include 1) understanding science, 2) practical skills and patient management, 3) holistic care (comprehensive care, which considers the physical, emotional, social, economic, and spiritual needs), 4) prevention, 5) interpersonal skills, 6) confidence and coping skills, 7) collaboration, and 8) self-directed learning (see details in Table 1).

\section{Analyses}

Each item on the survey had a response scale to a question beginning with the phrase "my medical education prepared me to..." rated from 1 to 4 , with 1 = "Very inade- 
Table I: Survey items by domain: "My medical education prepared me to.."a

\begin{tabular}{ll}
\hline Item & Description \\
\hline I. & Domain I: Understanding Science \\
2. & Anderstand the cellular basis of disease \\
3. & Justify drug uses on the basis of their mechanisms of action \\
4. & Select drugs on the basis of their costs, risks and benefits \\
\hline & Domain 2: Practical Skills and Patient Management \\
5. & Record clinical data systematically \\
6. & Carry out an efficient physical examination \\
7. & Carry out basic ward procedures \\
& $\quad$ a. Recording blood pressure \\
b. Inserting an intravenous line \\
$\quad$ c. Digitorectal exam \\
d. Inserting a urinary catheter \\
8. Carry out basic surgical procedures (eg, suturing) \\
9.
\end{tabular}

\footnotetext{
Domain 3: Holistic Care

10. Evaluate the impact of family factors on illness

11. Understand the interaction of social factors with disease (eg, poverty, unemployment)

12. Appreciate the importance of a patient's cultural/ethnical and religious background
}

\footnotetext{
Domain 4: Prevention

13. Take a drug and alcohol history with an initial consultation

14. Encourage patients to improve their health habits (e.g., unhealthy food, obesity, smoking...)

15. Provide education to patients and families about prevention of disease
}

\begin{tabular}{l} 
Domain 5: Interpersonal Skills \\
16. Feel competent to tell a patient that they have a terminal illness \\
17. Deal with dying patients and their family \\
18. Feel competent to counsel a distraught patient \\
\hline \\
19. Domain 6: Confidence/Coping Skills \\
20. Balance my work and personal life \\
21. Remain calm in difficult situations \\
22. Approach confidently senior staff for help in interpreting investigations
\end{tabular}

\section{Domain 7: Collaboration}

23. Be sensitive to the needs of nursing staff

24. Be able to coordinate a comprehensive patient management plan with other specialists and allied health professionals (eg, physiotherapists)

25. Appreciate the importance of group dynamics when working within a team environment

Domain 8: Self-Directed Learning
26. Invest time in developing my knowledge and skills
27. Keep up to date with medicine

a Summary of responses (\%) within each item are presented in Figure I.

quately", 2 = "Somewhat inadequately", 3 = "Somewhat adequately", and 4 = "Very adequately". Domain scores were calculated for each respondent by taking the mean response (scale 1-4) for the set of items within each domain. An overall score was computed as well by taking the mean response over all of the items. In all cases, higher scores indicate higher feelings of adequacy in preparedness within the given domain. The domain scores were summarized using median and interquartile range (IQR). To supplement the presentation of domain scores, the item level responses were summarized graphically. For this summary, the two response options for inadequacy ("very inadequate" + "somewhat inadequate") were combined into a single "inadequate" category. For interpretation purposes, performance was considered to be "deficient" for items rated as "inadequate" by $\geq 25 \%$ of students. The 
cut-off of $25 \%$ was arbitrarily selected as a realistic expectation for evaluating achievement and was determined prior to evaluating the results.

\section{Results}

The survey response rate was $61 \%(147 / 240)$, and $60 \%$ of respondents were females. Table 2 shows how graduates rated overall satisfaction with their education. The majority of graduates $(71 \%)$ were only "somewhat satisfied", while similar proportions were "fully satisfied" (12.9\%) or "dissatisfied" (15.7\%). The primary educators during hospital rotations in Zagreb were 'multiple educators' which include professors, specialists, and/or residents.

In considering responses regarding confidence in major educational domains, the median domain score was $\geq 3.0$ ("Somewhat adequate") for 7 of 8 domains, while 1 domain (interpersonal skills) had a median score of 2.0 ("Somewhat inadequate") (Table 3). Only the score that describes confidence within the preventive medicine area achieved responses close to the "very adequate" level. Results for all item level responses are graphically shown in Figure 1. For each item, we considered the response as inadequate (shown as black shaded area in histograms) when at least $25 \%$ of students rated the item as "Somewhat inadequate/Very inadequate"). Using these criteria, Zagreb graduates had a relatively high number of deficient items $(12 / 27,44 \%)$. Within the first domain (D1, Table 1, Figure 1) selection of drugs in regard to their cost, risks and benefits was a deficient item. Within D2 domain (D2, Table 1, Figure 1) basic surgical skills and inserting urinary catheters were deficient items. All other deficiencies are based on certain aspects of interpersonal skills such as dealing with patients, nursing staff, or balancing work and personal life (D5 domain: items 16-18, D6 domain: items 20 and 21, D7 domain: items 23 and 34, Table 1, and Figure 1).

Table 2: Overall satisfaction with medical education and role of primary educator

\begin{tabular}{lc}
\hline Characteristic & Zagreb \\
& N = I47 \\
\hline Satisfaction with education & $\mathbf{N}(\%)$ \\
$\quad$ Strongly satisfied & $19(12.9)$ \\
$\quad$ Somewhat satisfied & $105(71.4)$ \\
$\quad$ Somewhat/strongly dissatisfied & $23(15.7)$ \\
Primary educator during hospital rounds $t$ & \\
I worked mostly on my own & $0(0)$ \\
Intern & $4(2.7)$ \\
Resident/fellow & $0(0)$ \\
Specialist/Consultant & $43(29.5)$ \\
Multiple staff & $99(67.8)$
\end{tabular}

†Missing I response; \#Interaction with multiple educators during rotations; $\mathrm{N}$, number
Table 3: Main domain scores for Zagreb Medical School graduates

\begin{tabular}{lc}
\hline Main Domain & Zagreb $(\mathbf{N}=147)$ \\
\hline I. Understanding Science & Median $\left(\mathbf{2 5}^{\text {th }}, \mathbf{7 5}^{\text {th }}\right)$ \\
\hline 2. Practical Skills \& Patient Management & $3.00(2.75,3.25)$ \\
\hline 3. Holistic Care & $3.00(2.75,3.38)$ \\
\hline 4. Prevention & $3.33(3.00,3.67)$ \\
\hline 5. Interpersonal Skills & $3.67(3.00,4.00)$ \\
\hline 6. Confidence/Coping Skills & $2.00(2.00,2.67)$ \\
\hline 7. Collaboration & $3.00(2.50,3.25)$ \\
\hline 8. Self-Directed Learning & $3.00(2.67,3.33)$ \\
\hline Overall score & $3.00(3.00,4.00)$ \\
\hline
\end{tabular}

*Score range from I to 4 for each item (see Methods). Higher scores indicate feelings of more adequate learning while low scores indicate feelings of inadequate learning.

\section{Discussion}

We report survey results from the last generation of Medical School in Zagreb (graduating year 2006) who completed their medical education under traditional teaching, before the new educational initiative was introduced. The main finding of our survey is that graduates expressed relatively low confidence in several competences regarding their preparedness for their upcoming internship. Graduates reported low scores regarding skills in discussing terminal disease, dealing with a dying patient, and counseling distraught patients. Direct communication with patients and conveying important information regarding seriousness of their illness is not a part of the educational curricula during the 6 year medical training in Croatia. Terminally ill patients in Croatia are rarely informed by the physician regarding their poor prognosis, and more typically the "bad news" is communicated first to the family members, and later, depending on circumstances, to the patient. Interestingly, several other deficiencies identified amongst Zagreb graduates are also related within domains of interpersonal skills such as dealing with nursing issues or issues related to balancing work and personal life.

Another apparent deficiency was in the domain of basic clinical skills. Zagreb graduates were confident in elementary clinical skills such as measuring blood pressure, but they felt less prepared in performing simple procedures (such as minor surgical interventions, venipuncture, etc.) 


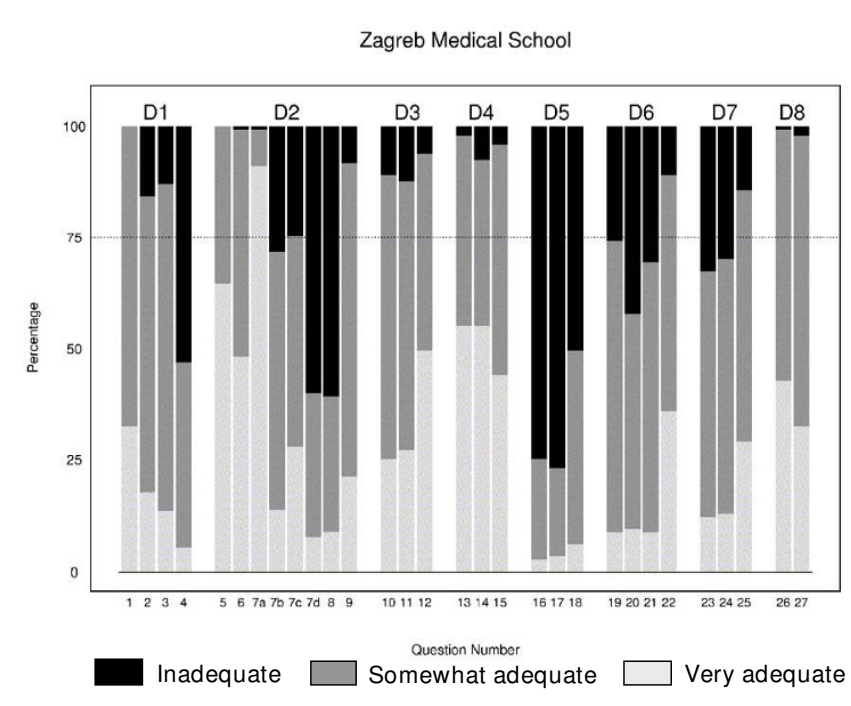

Figure I

Response percentages for each item within the 8 surveyed domains. For simplicity of graphical presentation, we combined two response options for inadequacy ("Somewhat inadequate" and "Very inadequate") into a single "inadequate" (black shaded) category. Achievement for a given item was considered deficient if $\geq 25 \%$ respondents rated the item as "inadequate". A reference line at $75 \%$ is provided to help distinguish "inadequate" from "adequate items". Domain titles and item details are provided in Table I.

or placement of urinary catheters. Measuring of the blood pressure represents the part of the initial patient examination (along with chest auscultation, and determination of pulse rate), and Zagreb medical students are routinely involved in this process, while the procedures such as insertion of urinary catheters, intravenous lines etc., are more frequently observed than performed. These finding are not unique for Croatian medical students. Similar findings were identified in other Western medical programs, [22] and despite improvements in education over the last decade, they continue to persist.[8] A recent report from Britain demonstrated that their interns showed low preparedness in treating minor injuries, [23] and this was not different from an earlier British report which showed that the undergraduate preparation was deficient in some practical procedures, common clinical conditions, and communication skills [24]. Finally, two categories indicated by Zagreb graduates as deficient were lack of confidence when faced with stressful situations and coordination of complex patient management situations. This is not surprising as these types of competences are usually acquired during postgraduate training.

Several factors may be postulated as responsible for the lower levels of self-perceived preparedness in some educational domains among Zagreb graduates. First, Zagreb stu- dents participate less in direct patient interaction, clinical decision-making and conducting supervised diagnostic and therapeutic procedures compared to students in Western European or United States educational systems (personal experience JS, KB). In these systems, students take night calls, conduct supervised patient admissions, and follow the patients throughout their hospital stay which may effectively increase knowledge and subsequent confidence. In Zagreb, students observe rather than perform invasive clinical procedures, and this lack of participation may reflect in lower confidence. Second, students in Zagreb acquire clinical skills largely from multiple educators (specialists, professors), while in Western medical educational systems, students receive the majority of clinical knowledge from working with residents and fellows. It is likely that more intense collaborative interaction between medical students and residents, in which workload is shared, has an impact on the education. Third, one of the disadvantages related to Croatian higher education may be associated with the lower financial compensation for physicians, which may affect motivation to teach. Finally, limited personnel resources and burdens on clinicians to complete their clinical duties simultaneously with teaching may diminish the motivation to invest time with students.

Among surgical residents, Kwasnik et al.[25] showed a good correlation between self-evaluation scores and specific clinical performance (knowledge, clinical judgment, and technical ability). At the same time, identification of the level of confidence [15] in specific clinical domains represents an important educational tool which may be used to directly target deficient areas.[16,17]

Ongoing reform in Croatian medical education $[19,20]$ is introducing broader contact between medical student and patients, and more independence (albeit supervised) in performing diagnostic and therapeutic procedures. One of the aims of the educators is to identify areas which students consider to be deficient. This is what our survey has accomplished. Because the present survey assessed the students' belief of ability to function as competent young doctors before the initiation of the reform, our observation may serve as guidance for educational improvements and a baseline for comparison of achievements after their implementation.

\section{Limitations}

When interpreting the results of this investigation there are several potential limitations. First, we report the findings from a single medical school; therefore, the results cannot be generalized to other medical schools in Croatia. Second, the survey instrument "Preparedness for hospital practice" was originally administered to practicing doctors,[21] and not students, and they were asked to rate 
their preparedness looking retrospectively at their undergraduate training. In the present study, the survey was administered to graduating medical students in anticipation of their work as junior doctors, and the potential exists that these students have little insight into what would be required for them, since they have no actual work experience. Although this questionnaire was not validated on a student population, we believe our results may help to identify some deficiencies and this information may be used to direct medical education.

\section{Conclusion}

In conclusion, we identified several major areas of clinical competence that could be improved among Zagreb medical students. Since Croatian education is currently undergoing reform, our results may be used to guide these changes as well as provide a point of reference to assess improvements upon completion of the educational reform.

\section{Abbreviations}

OSCEs: Objective Structured Clinical Examinations; QR: interquartile range.

\section{Competing interests}

The authors declare that they have no competing interests.

\section{Authors' contributions}

KB (study design, interpretation and collection of data, and writing the manuscript). DRS, GJS, SMJ (performed the analyses, interpretation of data, and writing the manuscript). DOW, JS (study design, interpretation of data, and writing the manuscript). All authors read and approved the final manuscript.

\section{Acknowledgements}

We are indebted to Sarah Hyde for providing us with the template of survey questionnaire. We are very thankful to Professors Matko Marušić (Dean of Medical School Split, Croatia, and Professor of Physiology, Medical School Zagreb, Croatia) and Željko Dujić (Head of Department of Physiology, Medical School Split, Croatia) for giving us insights regarding ongoing educational initiatives in Croatian medical schools.

\section{References}

I. Dean SJ, Barratt AL, Hendry GD, Lyon PM: Preparedness for hospital practice among graduates of a problem-based, graduate-entry medical program. Med J Aust 2003, I78(4): 163-166.

2. Objective structured clinical examination [http://en.wikipe
[ dia.org/wiki/Objective structured clinical examination]

3. Abrams RG, Kelley ML: Student self-evaluation in a pediatricoperative technique course. J Dent Educ 1974, 28(7):385-391

4. Das M, Mpofu D, Murdoch C, Bener AB: Role of peer appraisal and self-assessment during learning in community settings. Education for Health: Change in Training and Practice 1996, 9(2):239-249.

5. Henbest RJ, Fehrsen GS: Preliminary study at the Medical University of Southern Africa on student self-assessment as a means of evaluation. J Med Educ 1985, 60(I):66-68.

6. Pokorny AD, Frazier SH Jr: An evaluation of oral examinations. J Med Educ 1966, 4 I(I):28-40.
7. Barnsley L, Lyon PM, Ralston SJ, Hibbert EJ, Cunningham I, Gordon FC, Field MJ: Clinical skills in junior medical officers: a comparison of self-reported confidence and observed competence. Med Educ 2004, 38(4):358-367.

8. Coberly L, Goldenhar LM: Ready or not, here they come: acting interns' experience and perceived competency performing basic medical procedures. J Gen Intern Med 2007, 22(4):49I-494.

9. Jones A, McArdle PJ, O'Neill PA: How well prepared are graduates for the role of pre-registration house officer? A comparison of the perceptions of new graduates and educational supervisors. Med Educ 200I, 35(6):578-584.

10. Woolliscroft JO, TenHaken J, Smith J, Calhoun JG: Medical students' clinical self-assessments: comparisons with external measures of performance and the students' self-assessments of overall performance and effort. Acad Med 1993, 68(4):285-294.

II. Morgan PJ, Cleave-Hogg D: Comparison between medical students' experience, confidence and competence. Med Educ 2002, 36(6):534-539.

12. Weiss PM, Koller CA, Hess LW, Wasser T: How do medical student self-assessments compare with their final clerkship grades? Med Teach 2005, 27(5):445-449.

13. Westberg J, Jason H: Fostering learners' reflection and selfassessment. Fam Med I994, 26(5):278-282.

14. Albert Bandura [http://en.wikipedia.org/wiki/Albert Bandura]

15. Bandura A: Self-efficacy. In Encyclopedia of human behavior 4th edition. Edited by: Ramachaudran VS. New York: Academic Press; |994:7|-8|.

16. Clark MC, Owen SV, Tholcken MA: Measuring student perceptions of clinical competence. J Nurs Educ 2004, 43( I 2):548-554.

17. Whitehouse CR, O'Neill P, Dornan T: Building confidence for work as house officers: student experience in the final year of a new problem-based curriculum. Med Educ 2002, 36(8):718-727.

18. The Bologna Declaration on the European space for higher education: an explanation [http://ec.europa.eu/education/poli
[ cies/educ/bologna/bologna.pdf]

19. The European Higher Education Area-Achieving the Goals [http://www.bologna-bergen2005.no/Docs/00-Main docl 050520 Bergen Communique.pdf]

20. Nyborg P: Principles and objectives of the Bologna Process. International Conference, Chisnau, 25-28 November 2004.

21. Hill J, Rolfe IE, Pearson SA, Heathcote A: Do junior doctors feel they are prepared for hospital practice? A study of graduates from traditional and non-traditional medical schools. Med Educ 1998, 32(I): 19-24.

22. Fincher RM, Lewis LA: Learning, experience, and self-assessment of competence of third-year medical students in performing bedside procedures. Acad Med 1994, 69(4):291-295.

23. Croft S], Kuhrt A, Mason S: Are today's junior doctors confident in managing patients with minor injury? Emerg Med J 2006, 23( I I):867-868.

24. Jolly $B C$, MacDonald MM: Education for practice: the role of practical experience in undergraduate and general clinical training. Med Educ 1989, 23(2): 189-195.

25. Kwasnik EM, Carter J: To see ourselves as others see us: self assessment in surgical residency. J Surg Educ 1999, 56(3): | 45-| 48.

Publish with Bio Med Central and every scientist can read your work free of charge

"BioMed Central will be the most significant development for disseminating the results of biomedical research in our lifetime. "

Sir Paul Nurse, Cancer Research UK

Your research papers will be:

- available free of charge to the entire biomedical community

- peer reviewed and published immediately upon acceptance

- cited in PubMed and archived on PubMed Central

- yours - you keep the copyright 